\title{
CoMUNiCAÇão E INCLUSÃo de CRIANÇAS COM ALTERAÇõeS dE LINGUAGEM DE ORIGEM NEUROLÓgica Na PERSPECTIVA de PAIS E EdUCADORES
}

\author{
COMMUNICATION AND INCLUSION OF CHILDREN WITH LANGUAGE DISORDERS DUE TO \\ NEUROLOGIC ASPECTS FROM THE PERSPECTIVE OF PARENTS AND TEACHERS
}

\author{
Érica Mayumi TAKASE ${ }^{1}$ \\ Regina Yu Shon CHUN ${ }^{2}$
}

RESU M 0: o sistema de educação brasileiro tem passado por diversas transformaç̃̃es em prol de mudanças queproporcionem uma política inclusiva. Estudos relativos à comunicação einclusão de crianças com alterações delinguagem de origem neurológica necessitam, no entanto, demaior atenção, particularmenteno âmbito da Fonoaudiologia. Tendo em vista buscar maiores subsídios de como o profissional desta área pode contribuir no processo de inclusão, o objetivo deste estudo é investigar as expectativas, dificuldades e facilidades encontradas pelas famílias e educadoras de crianças com alterações de linguagem em acompanhamento fonoaudiológico. $\mathrm{O}$ corpus constitui-se de 11 crianças, 12 familiares e 7 educadoras. Realizou-se a coleta de dados, por meio de estudo do prontuário institucional das crianças, e entrevistas semi-estruturadas distintas com os familiares eeducadoras, gravadas em vídeo etranscritas ortograficamente. Os dados foram anal isados à luz dos referenciais teóricos querespal dam esta pesquisa. Os resultados mostram dificuldades na inserção de al gumas crianças na rederegular, particularmente, daquelas com maior comprometimento delinguagem, além de questionamentos quanto à formação do educador e preparo das instituições de ensino para receber tal população. Verificam-se avanços neste processo, expressos pela inclusão da maioria dos sujeitos na escola regular epor maior abertura institucional, evidenciada pelas referências detroca deinformações/ experiências entre pais, educadoras e fonoaudiólogos. Os achados corroboram, na perspectiva dos familiares e das educadoras, a necessidade do acompanhamento terapêutico especial izado eevidenciam quea Fonoaudiologia pode contribuir, nos aspectos de comunicação e de alimentação, no processo de inclusão.

PALAVRAS-CHAVES: educação especial; linguagem; inclusão; pais; educadores; fonoaudiologia.

ABSTRACT: The Brazilian educational system has been going through several modifications to answer to changes in inclusive policies. Studies regarding communication and inclusion of children with language disorders due to neurological causes require further attention, specifically in Speech-Language and Hearing Sciences. For the purpose of finding out how professionals in thisfield can contributeto theinclusion process, the aim of the study is to investigate the expectations, difficulties and support encountered by families and teachers of those children who undergo Speech-Language Pathology therapy. The corpus is composed of 11 children, 12 parents and 7 educators. The data was collected through the study of the children files, as well as

\footnotetext{
${ }^{1}$ Fonoaudióloga formada pela Universidade Estadual de Campinas com aprimoramento de Fonoaudiologia em N eurologia pelo Programa de A primoramento da Faculdade deCiências Médicas da UniversidadeEstadual de Campinas. Fonoaudióloga da APAE (Associação de Pais e A migos dos Excepcionais) de Santa Bárbara D'Oeste(SP). erikinha_may@yahoo.com.br

${ }^{2}$ Fonoaudióloga, Pós-Doutora em Linguística pela Universidade Estadual de Campinas e Docente do Curso de Graduação em Fonoaudiologia e do Programa de Mestrado Profissional Saúde, Interdisciplinaridade e Reabilitação da Faculdade de Ciências Médicas da Universidade Estadual de Campinas (SP). reginayu@fcm.unicamp.br
} 
from semi-structured interviews with families and teachers, video-recorded and transcribed orthographically. The data was analyzed according to references that support thisstudy. The results show challenges in including some of the children in regular schools, particularly those with the most severelanguagedisorders. There were also issues related to the preparation of theeducators and the preparedness of someof theschools that received thesestudents. Nevertheless, thestudy demonstrated that therehavebeen advances, expressed by theinclusion of most of these children in regular schools and by greater willingness of the schools to receivethese students. This finding was deduced from references to parents, educators and Speech-Language Pathologists sharing of information and experiences. From the perspective of the families and teachers, the findings point to the need for specialized health assistanceand highlight the contribution of the Speech-Languageand Hearing Sciences in communication and feeding in the process of inclusion.

KEYWORDS: Special Education; Language; Inclusion; Parents; Educators; Speech-Language and Hearing Sciences.

\section{InTRODUÇão}

A educação constitui-se como partede um conjunto de direitos sociais, previstos pela Constituição Brasileira, que visa garantir a diminuição da desigualdade entre as pessoas. Segundo Vitaliano (2007), o sistema de educação brasileiro tem passado por diversas transformações em prol de mudanças que proporcionem uma política inclusiva, com vistas ao atendimento educacional especial izado gratuito aos alunos com necessidades especiais, preferencialmente, na rederegular de ensino. Entretanto, como aponta esta autora, as institui ções de ensino ainda necessitam atender tais demandas.

A educação inclusiva, segundo as propostas do Ministério daEducação, visa "transformar as escolas públicas brasileiras em espaços inclusivos e de qualidade, que valorizem as diferenças sociais, culturais, físicas e emocionais e atendam às necessidades educacionais de cada al uno" (PAULON , 2005, p. 5). Para tanto, a autora salienta a necessi dade de uma política de educação inclusiva efetiva e duradoura, com reforma na gestão e no projeto pedagógico de cada escola, fundamentada na atenção à diversidade eno direito gl obal à educação.

Como pontuam Gomes e Barbosa (2006), apenas a presença destas crianças em escolas regulares não é suficiente. Tais autores indicam a necessidade de reformulações no sistema educacional do país para queestes al unos possam ser incluídos nas salas regulares das redes de ensino pública e privada, a partir de propostas eestratégias educacionais ede convivência voltadas à maioria dos alunos, amenizando-se, assim, as limitações edificuldades destegrupo populacional neste processo.

Segundo M artins (2001), vários estudos apontam que, frequentemente, crianças com necessi dades educacionais especiais são segregadas da escola antes deterem a oportunidade de al fabetização e de adaptação ao ambiente eao contexto escolar.

Diante destas questões, Paulon (2005) pontua que propostas individualizadas eespecíficas deensino eaprendizagem, para tais alunos, reforçam o processo deexclusão social eescolar. Segundo a autora, para se efetivar ainclusão 
escolar éimportante fundamentá-la em flexibilizações curriculares, considerandose tal grupo de alunos em sua diversidade.

Algumas das ações que poderiam contribuir para a gradativa implementação da inclusão do aluno com necessidades educacionais especiais no ensino regular, na perspectiva de Monteiro e Manzini (2008), dizem respeito à oferta decursos de capacitação, diminuição do número dealunos por sal a deaula regular, trabal ho em conjunto do professor especializado/ professor do ensino regular, entre outras ações.

A utores como Melo eM artins (2007) indicam a necessidade demudanças atitudinais, pedagógicas, comunicacionais e arquitetônicas, em função das particularidades decada instituição escolar, para quese efetiveo processo deinclusão. Além disso, apontam a importância do envolvimento de uma equipe multi ou interdisciplinar, fornecendo assistência e subsídios nas áreas de competência profissional para integração e acompanhamento das atividades desenvolvidas com estes al unos e desenvol vimento de uma prática inclusiva articulada ao educador.

Dentre os vários profissionais de Saúde e Educação necessários neste processo, esteartigo volta-seao papel do fonoaudiólogo, especialmenteem relação às crianças com alterações de linguagem decorrentes de causas neurológicas, por setratar detemática ainda pouco expl orada na Fonoaudiologia. Embora, em outras áreas, como na surdez, por exemplo, haja maior desenvolvimento de estudos voltados às questões de inclusão, como os trabalhos de Lacerda (2006); Rios e N ovaes (2009) eTenor et al . (2009), entreoutros.

Melo eFerreira (2009), em estudo acerca do aluno com deficiência física na Educação Infantil, no contexto da Fisioterapia, destacam a necessidade de parceria entreprofissionais deSaúdeeeducadores, além deindicarem a importância atribuída a el es na equipeescolar, particularmente o fisioterapeuta, no depoimento dos professores.

Serapompa eMaia (2006) apontama Educação ea Fonoaudiologia como parcei ras na reflexão dos referenciais de linguagem para as práticas de ensino e de aprendizagem, a partir do estudo de caso de uma criança com Síndrome deDown em seu processo de escolarização. Os resultados revelam que a crença, de pais e professores, no desenvolvimento do aluno e o diálogo estabelecido entre os profissionais, a família e a criança, favoreceu o desenvolvimento de situações de comunicação em um ambiente acolhedor da diversidade, fundamental em um processo de inclusão, e que depende da participação de diferentes atores sociais, no caso, educadores efonoaudiólogos.

Ramos eA Ives (2008) colocam quea contribuição do fonoaudiólogo na Educação pode se realizar a partir da criação de condições favoráveis e eficazes para que as capacidades de cada al uno possam ser otimizadas. N estecontexto de inclusão e integração, a comunicação assume grande importância, uma vez que, quanto mais efetiva, maiores são as chances de inserção do aluno com necessidades 
especiais no contexto escolar. Para Martins (2001), o aumento da capacidade de comunicação amplia a chance de aceitação dentro da sala de aula, independentemente de sua condição especial.

A autora assinala que a participação do fonoaudiólogo, juntamente com outros profissionais deEducação (e, acrescentaríamos, de Saúde), na atuação com os al unos regulares, pode ser realizada por meio de discussões e reflexões sobre comunicação e outros aspectos dos alunos com necessidades especiais, de modo a melhor compreender suas dificuldades e diferenças e a favorecer a integração, não só no ambiente escolar como também em outros contextos.

A lém disto, como esclarece Reis (2002), o fonoaudiólogo podecontribuir com subsídios e propostas de recursos facilitadores de linguagem, para o aluno com necessidade especial, respeitando-se a individual idade e singularidade de cada um. Assim, verificam-se, de modo geral, as possibilidades de atuação do fonoaudiólogo no processo de inclusão dealunos com necessidades educacionais especiais, tanto em escolas regulares quanto em escolas especiais.

Contudo, cabe particularizar eadensar tais questões, tendo em vista a comunicação ea inclusão de crianças com alterações de linguagem decorrentes de quadros neurológicos. A ssim, esteestudo justifica-se pela carência desteenfoque na literatura, com vistas à maior compreensão da temática eao aprimoramento da atenção fonoaudiológica para este grupo populacional. Portanto, o objetivo é investigar as expectativas, facilidades e dificuldades enfrentadas pelas famílias e educadores de tais crianças.

\section{MÉTOdo}

Trata-se deum estudo transversal, de abordagem qualitativa, quesegue a Resolução 196/ 96 da CONEP (Comissão N acional de Ética em Pesquisa), tendo sido aprovado pelo Comitê de Ética sob no 562/2008. O corpus constitui-se de 12 familiares ( 10 mães e os pais de uma criança) e 7 educadoras de 11 crianças, com alterações de linguagem decorrentes de causas neurológicas, atendidas no Programa deA primoramento deFonoaudiologia em N eurologia da Faculdade de Ciências Médicas da Universidade Estadual de Campinas.

Realizou-se a coleta de dados por meio do estudo dos prontuários institucionais, para caracterização do perfil sociodemográfico, educacional e de linguagem das crianças, e entrevistas semi-estruturadas com seus familiares e educadoras, das escolas por elas frequentadas, gravadas em vídeo e transcritas ortograficamente.

A s entrevistas com as educadoras foram realizadas em seus ambientes de trabal ho e, com os familiares, no local de acompanhamento fonoaudiológico das crianças, no CEPRE (Centro de Estudos e Pesquisas em Reabilitação Prof. Dr. Gabriel O. S. Porto)/ UNICAMP. 
Cada grupo de entrevistados respondeu a um questionário distinto, contendo 15 questões, com respostas abertas etempo deaplicação livre.

Os temas abordados com os familiares abrangeram a participação na vida escolar do filho; o modo de lidar com sua linguagem; o relacionamento da criança com colegas e professoras; o atendimento especializado recebido; o preparo das escolas em relação às necessidades especiais do filho; as dificuldades e facilidades de inclusão escolar e como a Fonoaudiologia poderia auxiliar neste processo.

As questões apresentadas às educadoras voltaram-se ao processo de inclusão escolar das crianças sob sua responsabilidade; a participação dos pais na vida escolar destes alunos; as dificuldades e facilidades na atuação com estas crianças; seu relacionamento no contexto escolar ecomo a Fonoaudiol ogia poderia auxiliar neste processo. esta pesquisa.

Os dados foram analisados à luz dos referenciais teóricos que respaldam

\section{RESULtAdOS E DISCUSSÃo}

A presenta-se parte dos resultados das entrevistas com os familiares e educadoras. A faixa etária das mães situa-se entre 29 e 45 anos, o grau de escolaridade varia entre ensino fundamental incompleto e ensino superior completo, sendo queoito são donas decasa, duas são domésticas euma éprofessora aposentada. O pai tem 43 anos, ensino técnico completo etrabal ha como agricultor florista. A s educadoras encontram-se na faixa etária de 30 a 51 anos deidade, sendo que três são especialistas em Educação Especial. Segue o perfil demográficoeducacional, alterações fonoaudiológicas das crianças, além do tempo de acompanhamento fonoaudiológico no Programa de Aprimoramento de Fonoaudiologia em N eurologia, descritos no Quadro 1. 


\begin{tabular}{|c|c|c|c|c|c|c|c|}
\hline Sujeito & Idade & Sexo & $\begin{array}{l}\text { Hipótese } \\
\text { diagnóstica }\end{array}$ & Escola & Série & $\begin{array}{c}\text { Alteração } \\
\text { fonoaudiológica }\end{array}$ & $\begin{array}{c}\text { Tempo de } \\
\text { acompanhamento } \\
\text { fonoaudiológico }\end{array}$ \\
\hline S1 & 11 & $\mathrm{~F}$ & RDNPM & Regular & $\begin{array}{l}4^{\text {a }} \text { série } \\
\text { Ens. } \\
\text { Fund. }\end{array}$ & ALO e AMO & 3 anos e 4 meses \\
\hline S2 & 6 & $\mathrm{~F}$ & RDNPM & Regular & $\begin{array}{l}1^{\text {13 série }} \\
\text { Ens. } \\
\text { Fund. }\end{array}$ & ALO e AMO & 2 anos e 10 meses \\
\hline S3 & 6 & $\mathrm{~F}$ & Afasia Infantil & Regular & $\begin{array}{l}1^{\text {a }} \text { série } \\
\text { Ens. } \\
\text { Fund. }\end{array}$ & $\begin{array}{c}\text { ALO (NO e uso de } \\
\text { CSA) e AMO }\end{array}$ & 10 meses \\
\hline S4 & 5 & M & PC & $\begin{array}{c}\text { Nunca } \\
\text { frequentou }\end{array}$ & & ALO (NO) e AMO & 6 meses \\
\hline S5 & 11 & M & Autismo & Regular & $\begin{array}{l}4^{\text {a }} \text { série } \\
\text { Ens. } \\
\text { Fund. }\end{array}$ & ALO (OR) & 3 anos e 5 meses \\
\hline S6 & 7 & $\mathrm{~F}$ & PC & Especial & $\longrightarrow$ & ALO (NO) e AMO & 3 anos e 10 meses \\
\hline S7 & 7 & $\mathrm{~F}$ & RDNPM & Especial & & ALO (NO) e AMO & 3 anos e 2 meses \\
\hline S8 & 12 & $\mathrm{~F}$ & PC & Regular & $\begin{array}{l}4^{a} \text { série } \\
\text { Ens. } \\
\text { Fund. }\end{array}$ & $A L O, A M O$ e ALE & 3 anos e 10 meses \\
\hline S9 & 4 & $\mathrm{~F}$ & RDNPM & Não frequenta & 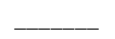 & ALO e AMO & 5 meses \\
\hline S10 & 11 & $\mathrm{~F}$ & RDNPM & Regular & $\begin{array}{l}3^{\text {a }} \text { série } \\
\text { Ens. } \\
\text { Fund. }\end{array}$ & ALO, AMO e ALE & 2 anos e 7 meses \\
\hline S11 & 10 & M & RDNPM & $\begin{array}{l}\text { Regular } \\
\text { (classe } \\
\text { especial) } \\
\end{array}$ & Educ. Inf. & $\begin{array}{c}\text { ALO (OR e uso de } \\
\text { CSA) }\end{array}$ & 2 anos e 10 meses \\
\hline
\end{tabular}

Quadro 1 - Perfil demográfico-educacional, alterações fonoaudiológicas das crianças etempo de acompanhamento fonoaudiológico

Fonte: Arquivos do Programa de A primoramento de Fonoaudiologia em Neurologia, FCM/ UNICAMP

Legenda: F - feminino; $M$ - masculino; RDN PM - retardo do desenvolvimento neuropsicomotor; PC - paral isia cerebral; Ens. Fund. - ensino fundamental; Educ. Inf. - educação infantil; ALE - alteração de leitura e escrita; ALO - alteração de linguagem oral; AMO - alteração de motricidade orofacial; CSA - comunicação suplementar e/ ou alternativa; NO - não oraliza eOR - oral idade restrita

Verifica-se, conforme demonstrado no Quadro 1, quea grandemai oria dos sujeitos está inserida em escola regular. Destas crianças, apenas uma frequenta classeespecial em escola regular eduas, escola especial. Os pais destas duas crianças, que frequentam escola especial, tentaram inseri-las em escola regular, porém, encontraram dificuldades neste sentido.

Todos os pais referiram considerar a educação como um fator essencial para o desenvolvimento, aprendizagem e social ização das crianças, sendo que a maioria procurou inserir seus fil hos na escola antes da época deingresso regular. Esta inserção, segundo dados das entrevistas, ocorreu por iniciativa própria ou por recomendação de profissionais (médicos ou fonoaudiólogos).

Metade dos familiares entrevistados referiu dificuldades de inserção e/ ou permanência de seus filhos na escola regular. Dentreos motivos, indicaram: dificuldades relacionadas aos aspectos motores; problemas de saúde; linguagem da criança; adaptação do filho com a professora; falta de acompanhamento especializado em sala deaula eoutras atividades que possi bilitassem a participação da criança na programação escolar. 
N a análise estatística, não foi encontrada correlação significativa entre tempo de acompanhamento fonoaudiológico e facilidade de inclusão escolar da criança. Os achados demonstram que os familiares de crianças com maior comprometimento delinguagem, como no caso daquelas não oralizadas, referiram encontrar maior dificuldade para a inserção e/ ou permanência na escola regular, como ilustra o depoimento de uma das mães (M 4):

Eu nem vi, foi uma colega, vizinha minha. Ela falou que, se eu não me importasse, queela queria estar conversando com a professora sobreo S4 na escola. Daí eu fal ei : tá, tudo bem. Daí, a professora perguntou seelefalava, se comunicava eela falou quenão, daí a professora falou que não aceitaria por causa disso.

Tais resultados coincidem com as colocações de Martins (2001), de que diferenças de comportamento, linguagem e rendimento escolar se constituem em al guns dos motivos pelos quais os al unos com necessidades especiais têm maior dificuldade em se inserir no ensino regular.

O preparo dos profissionais pode ser considerado um dos aspectos essenciais para queas dificuldades, apontadas por Martins (2001), não seconstituam em fator deexclusão escolar das crianças com necessidades educacionais especiais.

N este aspecto, a mai oria das educadoras entrevistadas (57\%) referiu ter recebido formação para atuar com tais alunos, sendo que outras duas (29\%) relataram ter poucos subsídios em sua formação, considerando o grau de aprofundamento não suficiente para a atuação com estas crianças e apenas uma (14\%) referiu que sua formação não Ihe forneceu base adequada para tanto.

Segundo Ramos e Alves (2008), é relevante que os profissionais que trabal hem com estes alunos conheçam seu desenvolvimento, considerando suas competências e formas de comunicação e realização das atividades. A pontam a importância deste conhecimento para a el aboração de propostas de trabal ho que visem potencializar a interação e participação da criança nos projetos curriculares, oferecendo desafios compatíveis com as possibilidades de cada aluno e, assim, promover a acessibilidade ao conteúdo programático.

Verifica-se, entre as educadoras, que uma parcela significativa (43\%) indicou encontrar facilidades no trabal ho com estes al unos, atribuindo tal fato à própria formação eà possi bilidade deatenção individualizada, como ilustra o relato deE6:

Sim, é fácil atuar como educadora em Educação Especial, desde que haja empenho por parte do profissional, atual izando sempre, pesquisando, lendo, se informando sobre as deficiências dos alunos. Buscando melhoria para a aprendizagem do al uno e para o seu desenvolvimento.

Duas educadoras (29\%) referiram encontrar dificuldades efacilidades na atuação com as crianças, justificadas pela sua formação e, outras duas (29\%), relataram encontrar mais dificuldades em atuar com elas. 
Quanto às razões que dificultam a atuação com estas crianças, as educadoras relacionaram: descrédito da família em relação ao potencial do filho; não aceitação de ajuda por parte dos pais; falta de atendimento terapêutico especial izado de al gumas crianças; dificuldades de al guns educadores para lidar com a diversidade e respeito às diferenças destes al unos; fal ta de acessi bilidade (adaptações físicas etecnológicas); falta deembasamento teórico; apoi o pedagógico especial izado, bem como de orientação à família.

Alguns destes fatores, relatados por estas profissionais, também aparecem nas entrevistas de uma parcela (25\%) dos pais, constituindo algumas das razões pelas quais os filhos foram inseridos em escolas ou salas especiais. Dentre estes aspectos, foi mencionada a falta de suporte especializado, que acarretou a permanência de uma mãe, em sala de aula com o filho, durante o período escolar.

Segundo as entrevistas, outros fatores coincidentes, entre educadores e familiares, que contribuíram para a opção de transferência da criança, do ensino regular para o ensino especial, foram: dificuldade da criança no processo escolar e falta deatividades que possi bi litassem a participação da criança em sal a deaula.

Todos os pais ( $n=10$ ), cujos filhos frequentam escola, caracterizaramna como ambiente preparado para educá-los, sendo que esta opinião não é compartilhada por grande parte (83\%) das educadoras, quejustificam esta situação pela falta de formação dos profissionais, dificuldades de acessibilidade, falta de suportetécnico edemateriais especial izados. Tais aspectos, segundo al gumas delas, prejudicam a proposta de inclusão.

No que diz respeito ao acompanhamento pedagógico ou terapêutico, na escola, a maioria dos pais (67\%) referiu que seus filhos recebem acompanhamento deoutros profissionais (entreeles, fonoaudiólogo epedagogo) ou reforço escolar. Contudo, todos os pais de crianças queestão na escola regular ( $67 \%$ do total de sujeitos) indicaram que não há um trabalho específico vol tado às al terações de linguagem ou deal imentação dos fil hos, diferentemente da situação das crianças que estão na escola de Educação Especial (17\% do total de sujeitos), cujos pais afirmaram que recebem orientação equeos filhos têm acompanhamento individual izado, voltado a estas questões.

Cabe ressaltar que não compete apenas aos profissionais da escola o esforço em prol da educação inclusiva. Vários autores, como Serapompa e Maia (2006), pontuam que pais ou familiares também podem favorecer a integração escolar e social das crianças com necessidades especiais, atuando como parcei ros ativos no processo detomada de decisão e planejamento da educação de seus filhos. N esta direção, A iello (2002) sal ienta a necessidade deencorajamento defamiliares para que participem de atividades educacionais, em casa ena escola, bem como na supervisão eapoio à aprendizagem deseusfilhos, criando, inclusive, oportunidades para queescolham o tipo de provisão educacional queacreditam ser mais adequado às suas crianças. 
Quanto à participação em reuniões escolares, grande parte (58\%) dos pais referiu frequentar todas as reuniões. Uma parcela (17\%) referiu não frequentar, pelo fato deseus filhos terem setransferido há pouco tempo para a instituição atual (na época da pesquisa). A penas uma mãe (8\%) indicou não poder comparecer às reuniões em função de incompatibilidade com o horário de trabal ho.

Em relação à inserção das famílias no processo de inclusão, na perspectiva das educadoras, a maioria (86\%) caracteriza os pais desta pesquisa como participativos e preocupados com as questões educacionais de seus filhos. Os achados demonstram, segundo elas, que são fornecidos esclarecimentos por parte da escola em relação ao processo educacional das crianças.

Como coloca A iello (2002), sem o desenvolvimento da parceria famíliaescola, além do nível equalidadedeenvolvimento necessário para queseassegurem ganhos educacionais para todas as crianças, dificilmente as metas do processo de inclusão serão al cançadas.

Em relação ao processo de escolaridade/ aprendizagem das crianças, dentre os pais cujos filhos frequentam escola, $42 \%$ observam mel hora significativa no desempenho escolar dos mesmos. Outros $25 \%$ consideram quea escolarização ocorre de forma satisfatória, 8\% quea aprendizagem varia conformeas matérias e os professores e $8 \%$ indicam que o filho sempre apresentou dificuldades.

Uma parte das educadoras entrevistadas (43\%) observa evolução dos al unos do estudo, outras $29 \%$ indicam que el es têm desempenho compatível com a idade, sendo que uma educadora (deescola especial) refere que o aluno apresenta desempenho compatível com suas limitações e potencial idades eoutra considera que seu desempenho lento.

No tocanteao relacionamento das crianças com as professoras ecolegas, tod os os pais relataram ser bom, etambém referiram quetanto as professoras quanto os outros alunos auxiliam e parecem compreender as dificuldades das crianças.

Quanto ao relacionamento com alunos de outras salas, duas mães relataram quesuas crianças passaram por situações de constrangimento eatribuem este fato à fal ta de informação dos demais al unos sobre as dificuldades de seus filhos, como ilustra o depoimento de M3, que se segue:

Então, na sala dela tá tudo normal, porque a professora conversou com eles. Mas, tem outras crianças queolham, ficam falando sobre la porquenão sabem o que aconteceu, não tem noção que ela teve um problema, e por isso usa o babador enão consegue ficar com a boca fechada. Uma coisa quetinha queser conscientizado é dos pais conversarem, da professora passar para os outros pais no dia da reunião, para ter o relacionamento igual.

A convivência com outras crianças, como destacam Tetzchner et al . (2005), em estudo relacionado à Comunicação Suplementar e/ ou Alternativa (CSA), é fundamental, por propiciar experiências queauxiliarão as crianças com necessidades 
especiais em seu desenvolvimento linguístico e social, como também a lidar com situações de diferentes conteúdos emocionais. Para tais autores, a oportunidade de incluir estas crianças em situações desafiadoras se configura como uma das justificativas rel evantes para a inclusão das mesmas. Pontuam quea indusão favorece a possibilidade de atividade conjunta, a troca de conhecimento, assim como as aproximam dos demais alunos. Além disso, assinalam que o processo de inclusão não éfavorável apenas às crianças com necessidades especiais, mastambém às outras crianças, por propiciar a oportunidade de reflexão e vivência desta experiência.

A referência sobre o bom relacionamento entre alunos, com e sem necessidades especiais, educadores e/ ou funcionários, do contexto escolar, também aparece no discurso da maioria (71\%) das entrevistadas. A pesar de proporção idêntica das educadoras considerarem as escol as ambientes não preparados para o processo de inclusão, o mesmo índice(71\%) considera que as crianças, do estudo, encontram-se inseridas e adaptadas ao ambiente escolar e atribuem este fato, em grande parte, à qualidade das relações estabelecidas. A penas a professora da instituição deensino especializada relata mai or preparo, do seu local detrabal ho, no que diz respeito ao apoio à criança. Os resultados evidenciam que a existência de uma equipe interdisciplinar favorece a atuação desta educadora, permitindo atenção mais individual izada aos al unos e seus familiares, minimizando, assim, as dificuldades deinclusão.

Neste sentido, Paulon (2005) ressalva que, muitas vezes, o que ocorre é uma política educativa que situa o professor como o responsável pela melhoria da educação brasileira, implicando constantes queixas destes profissionais perante as dificuldades no atendimento à diversidadedeseus alunos. Para o autor, um educador sozinho pouco pode fazer diante da complexidade de questões que envolvem o processo deinclusão escolar, considerando fundamental o envolvimento de uma equipe multi ou interdisciplinar, para que sepenseo trabalho educativo a partir dediversos campos deconhecimento ese construa uma prática inclusiva, junto ao professor.

Em relação à alimentação de seus filhos, a maioria (75\%) dos familiares demonstra preocupação em oferecer alimentos de preferência das crianças, facil itand o a mastigação por meio da introdução deal imentos mais pastosos ou de espessuras menores. Outros (25\%) indicaram oferecer aos filhos o mesmo cardápio da família, sem variar tipo, consistência nem espessura.

Quanto às questões de alimentação, na escola, na perspectiva dos familiares, a maioria (67\%) respondeu que não há acompanhamento especializado e são oferecidos os mesmos al imentos a todos os alunos, independente de suas necessidades especiais. Somente duas mães, cujas crianças frequentam escola especial, apontaram que as professoras procuram seguir as recomendações do profissional deFonoaudiologia, seja o que atua na própria escola ou fora dela.

No tocante às questões de linguagem, todos os pais $(n=12)$ referiram se preocupar comesteaspecto, porém, lidam com ele deforma variada. A maioria (67\%) estabelece comunicação própria ou tenta adivinhar o que a criança quer expressar; 
uma parte (25\%) pedepara repetir eapenas um familiar (8\%) referiu que o filho utiliza CSA, além de incentivar a fala dele, como demonstra o Gráfico 1:

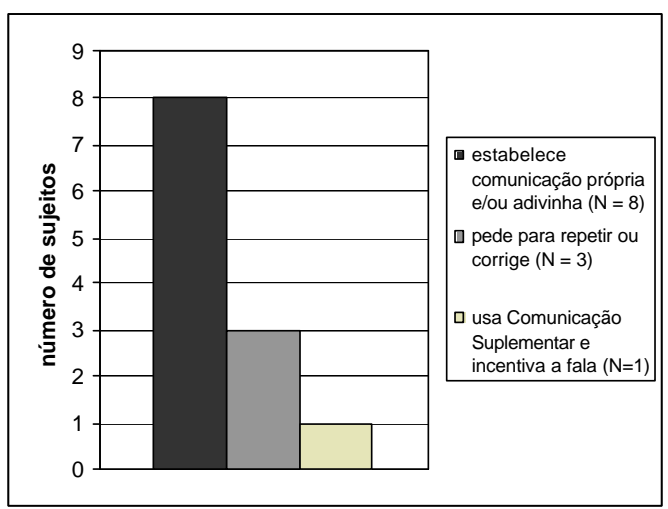

Gráfico 1 - Distribuição de como os pais lidam com a linguagem de seus filhos. Fonte: Arquivos do Programa deA primoramento deFonoaudiologia em N eurologia, FCM/ UNICAMP

As formas como as educadoras $(n=6)$ lidam com as questões de linguagem também se mostraram variadas, como demonstrado no Gráfico 2 . A maioria (67\%) indicou que procura dar maior atenção à criança; uma referiu encaminhamento à Fonoau diologia e outra, que não há um cuidado diferenciado em relação aos demais al unos.

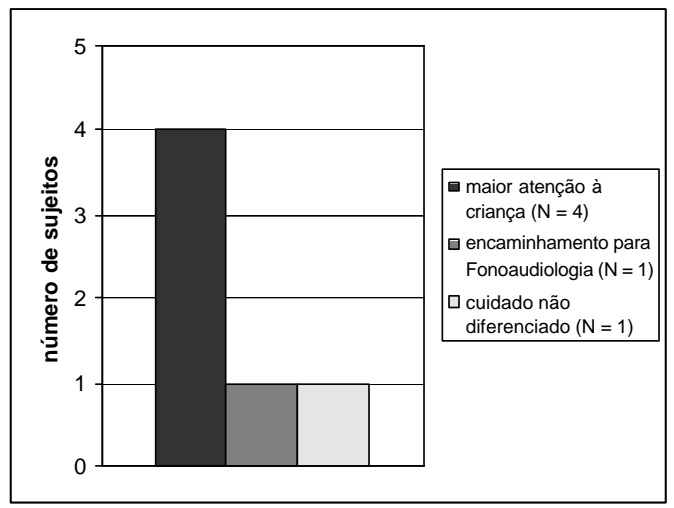

Gráfico 2 - Distribuição de como o professor lida com as questões de linguagem da criança.

Fonte: Arquivos do ProgramadeA primoramento de Fonoaudiologiaem Neurologia, FCM/ UNICAMP

No caso da criança que utiliza prancha de CSA, no contexto familiar, verifica-se que tal uso não é citado no ambiente escolar, sendo sugestivo de 
necessidade de maior aproximação entre o profissional de Fonoaudiologia, responsável pela introdução da CSA, ea escola.

Quanto às possibilidades de contribuição da Fonoaudiologia no processo deinclusão, na perspectiva dos pais $(n=12)$, a maioria $(58 \%)$ dos familiares salienta a necessi dade de atendimento fonoaudiológico, seja dentro do ambiente escolar (25\%) ou fora dele (33\%); três familiares indicaram a necessidade de orientação fonoaudiológica ao professor; um indicou a necessidade de orientação aos pais e, outro, referiu não saber responder, como demonstra o Gráfico 3.

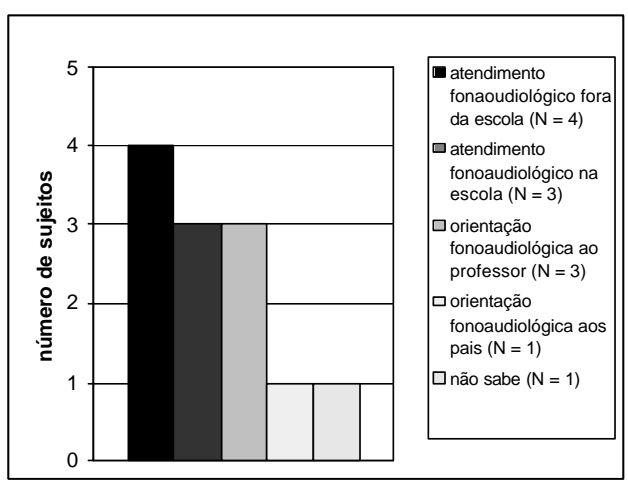

Gráfico 3 - Contribuição da Fonoaudiologia na inclusão escolar, na perspectiva dospais.

Fonte: Arquivos do ProgramadeA primoramento de Fonoaudiologiaem N eurologia, FCM/ UNICAMP

Osresultados mostram quea contribuição da Fonoaudiologia no processo de inclusão escolar, na perspectiva das educadoras $(n=6)$, remetem à troca de conhecimentos com o educador (50\%), necessidade de atendimento clínicoterapêutico (33\%) eorientação à escola (17\%), como demonstrado no Gráfico 4.

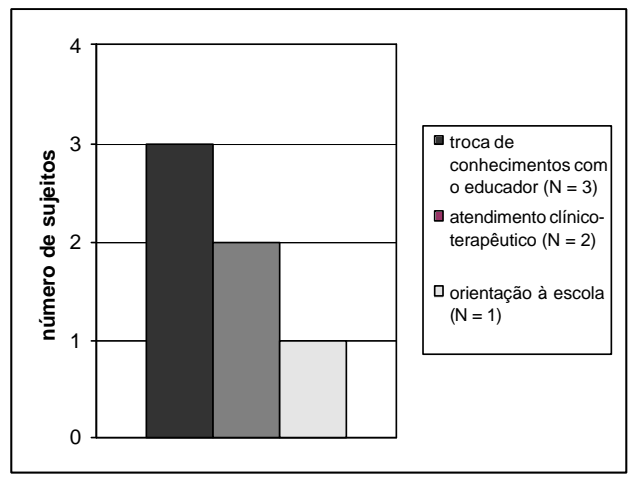

Gráfico 4 - Contribuição da Fonoaudiologia na inclusão escolar, na perspectiva das educadoras.

Fonte: Arquivos do Programa de A primoramento de Fonoaudiologiaem Neurologia, FCM/ UNICAMP 
Considerando-seo papel da comunicação na inclusão escolar, Martins (2001) aponta a relevância do trabalho fonoaudiológico com crianças com necessidades especiais, por setratar do profissional que atua nas áreas de linguagem oral eescrita, motricidade orofacial, voz eaudição. Esta parceria podeproporcionar projetos pedagógi cos quelevem em consideração as singularidades edificuldades decada al uno, favorecendo o processo de integração e inclusão.

\section{C ONCLUSÃO}

Os resultados mostram as expectativas, facilidades e dificuldades enfrentadas pelos familiares e educadoras no processo de inclusão educacional, particularmente, das crianças com maior comprometimento delinguagem, no caso, não oralizadas. Evidenciam questões relacionadas à formação das educadoras e ao preparo das instituições para receber crianças com alterações de linguagem decorrentes dequadros neurológicos.

Por outro lado, verificam-se os avanços e facilidades neste processo, demonstrados pela inclusão da mai oria dos sujeitos estudados na escola regular. Isto reflete uma maior abertura institucional, que se evidencia também nas referências de trocas de informações e experiências entre pais, educadoras e fonoaudiólogos.

Os achados apontam a necessidade de maior atenção terapêutica especial izada eatuação nas questões de comunicação elinguagem, na perspectiva dosfamiliares e educadoras, corroborando aspectos em quea Fonoaudiologia pode contribuir no processo de inclusão do grupo populacional estudado.

O processo deinclusão escolar, decrianças com al terações delinguagem decorrentes de quadros neurológicos, implica a colaboração e participação dos vários atores sociais envolvidos, ou seja, o esforço conjunto dos pais, da população edos profissionais de SaúdeeEducação, para queseconcretize, deforma cada vez mais eficaz.

Neste sentido, compreender as necessidades daqueles que atuam, diariamente, neste contexto, sejam familiares ou educadores, possibilita melhor direcionamento do trabal ho fonoaudiológico às demandas destas crianças, demodo a contribuir para o favorecimento do processo de aprendizagem e socialização, como também, mel hor qualidade de vida desta população.

\section{REFERÊNCIAS}

AIELLO, A.L.R. Família inclusiva. In: PALHARES, M. S.; MARINS, S. C. (Org.). Escola inclusiva. São Carlos: EdUFSCar, p.87-98, 2002.

GOMES, C.; BA RBOSA , A.J.G. Inclusão escolar do portador de paralisia cerebral: atitudes de professores do ensino fundamental. R evista Brasileira deE ducação Especial , Marília, v.12, n.1, p.85-100, 2006. 
LACERDA, C. B. F. A inclusão escolar deal unos surdos: o quedizem alunos, professorese intérpretes sobre esta experiência. Cadernos C edes, Campinas, v.26, n.69, p.163-184, 2006.

MARTINS, G.A.H. Refletindo sobrea atuação do fonoaudiólogo junto à educação especial. In: GIROTO, C. R. M. (Org.). Perspectivas atuais da Fonoau diologia na escola. São Paulo: Plexus Editora, 2001.

MELO, F.R.L.V.;FERREIRA, C.C. deA. O cuidar do aluno com deficiênciafísica na educação infantil sob a ótica das professoras. R evista Brasileira deE du cação Especial, M arília, v.15, n.1, p.121-140, 2009.

MELO, F.R.L.V. de; MARTINS, L. deA.R. A colhendo eatuando com alunos queapresentam paralisia cerebral na classe regular: a organização da escola. R evista B rasileira de E ducação Especial, Marília, v.13, n.1, p.111-130, 2007.

MONTEIRO, A. P. H.; MANZINI E. J. Mudanças nas concepções do professor do ensino fundamental em relação à inclusão após a entrada dealunos com deficiência em sua classe. Revista Brasileira de E ducação Especial, Marília, v.14, n.1, p.35-52, 2008.

PAULON, S.M. Documento subsidiárioà política deinclusão. In: PAULON, S. M.; FREITAS L. B. deL.; PINHO, G.S.P. (Org.). A nál ise de referenciais da educação especial . Brasília: Ministério da Educação, Secretaria de Educação Especial, 2005.

RAMOS, A.S; A LVES, L.M. A Fonoaudiologia na relação entreescolas regulares deensino fundamental e escolas de educação especial no processo de inclusão. R evista Brasileira de E ducação Especial , M arília, v.14, n.2, p.235-250, 2008.

REIS, K. A importância da Fonoaudiologia na Educação Especial. Fono A tual , n. 20, p. 58, 2002.

RIOS, N.V.F.; NOVAES, B.C.A.C. O processo de inclusão de crianças com deficiência auditiva na escola regular: vivências de professores. Revista Brasileira de Educação Especial, Marília, v.15, n.1, p.81-98, 2009.

SERA POMPA, M.T; MAIA S. M. A colhimento e inclusão: da clínica ao acompanhamento escolar deum sujeito com Síndrome deDown. R evista D istúrbios da Comunicação, São Paulo, v.18, n.3, p. 313-322, 2006.

TENOR, A.C. et al. A inclusão do aluno surdo no ensino regular na perspectiva de professores de um município de São Paulo. Revista D istúrbios da Comunicação, São Paulo, v.21, n.1, p.7-14, 2009.

TETZCHNER, S. et al. Including children using augmentative and alternative communication in ordinary preschools. Tradução de Lúcia H. Reily. Revista Brasileira de E ducação Especial, M arília, v.11, n.2, p.151-184, 2005.

VITALIANO, C. R. A nálisedas necessidades da preparação pedagógica de professores de licenciatura para inclusão de alunos com necessidades educacionais especiais. R evista Brasileira de Educação Especial, Marília, v.13, n.3, p.399-414, 2007.

Recebido em: 27/ 11/ 2009

Reformulado em: 20/ 04/ 2010

A provado em: 10/ 08/ 2010 